\title{
Combined pretreatment as an effective technology in breaking of phenolic polymer lignin from sustainable biomass:
} Bambusa balcooa

Heena Parveen*1, Lakshmi Tewari ${ }^{1}$, Diwas Pradhan ${ }^{2}$ and Parul Chaudhry ${ }^{1}$

$1{ }^{1}$ Department of Microbiology, College of Basic Science and Humanities, G.B. Pant University of Agriculture and Technology, Pantnagar, Uttarakhand, India

${ }^{2}$ Dairy Microbiology Division, National Dairy Research Institute, Karnal, Haryana, India

\begin{abstract}
Bamboo biomass is a potential source for the production of monomeric sugars containing high cellulose content with low amount of lignin. However, for efficient hydrolysis, the biomass treatment by effective pretreatment technique is required to minimize lignin content and other barrier components. During present study, the bamboo biomass was treated with different physical, chemical, biological and combined treatments to reduce the lignin content. Among all the pretreatments, the maximum lignin removal $(14.5 \%)$ was obtained with the combined chemical and biological treatment under $2 \% \mathrm{NaOH}+1 \% \mathrm{H}_{2} \mathrm{O}_{2}+$ WDP2 fungal culture (5 plugs) conditions. In addition, lignolytic fungus and $\mathrm{NaOH}$ pretreatment was mainly effective in removing lignin, whereas the $\mathrm{H}_{2} \mathrm{O}_{2}$ pretreatment efficiently minimize cellulose crystallinity. To analyze structural changes of raw and treated biomass, we used scanning electron microscopy and fourier transform infrared spectroscopy. The structural analysis indicated that all treatments causes disruption in the biomass structure and loses the compactness of the biomass which facilitates the biomass conversion during hydrolysis process. The findings of the present study indicate effective pretreatment methods in breaching the recalcitrancy of the potential lignocellulosic biomass for maximum hydrolysis.
\end{abstract}

Keywords: Bambusa balcooa, pretreatment; lignolytic fungus; SEM; FTIR

\section{Introduction}

The increased concern of worldwide energy demand has a noticeable effect on the economic sustainability and stability of the world [1]. In response, a key research area in biotechnology has centered on the biological conversion of lignocellulosic biomass to simple sugars via enzymatic hydrolysis of cell wall polysaccharides. This can be utilized to generate a variety of downstream fuels and chemicals that meets global energy demands and make an effort to reduce international dependency on conventional petroleum resources. Currently, most biorefinery strategies rely heavily on either biological conversion of lignocellulosic biomass or thermo-chemical processes to produce transportation fuels as the major process flow [2]. For the expansion of plant based eco-friendly fuel industry, the chosen biomass resource 
should be present on sustainable basis and also be affordable as the project sustainability is concerned. Bamboo, with its advantages of very fast growth rate, short renovation, and easy propagation, rich in cellulose and hemicellulose, and low lignin content, seems to be a potential feedstock for bio-ethanol or other bio-fuels production. There are 1500 bamboo species in the world and more than 20 million hactor of bamboo forests and plantation [3]. India is the second largest reserves of bamboo in the world. About $25 \%$ of bamboo species of the world are found in India distributed widely in almost all states. They are particularly abundant in the Western Ghats and the "Sister States "of North-east India [4]. The size of the Indian bamboo industry was estimated to be about Rs. 6505 crores that increased in 2015 to Rs. 26,000 crores and further grows rapidly. Bamboo has been recognized as the fastest growing plant species, with the harvestable time of 3-5 years versus 10-20 years for most of the softwood in the world with very favorable characteristics for gasification and the synthesis of gasoline and diesel. Its heating value is higher than most agricultural residues, grasses and straw. Besides bamboo has high biomass productivity, self-regeneration, bamboo can easily compete with the most effective wood species in terms of carbon sequestration capacities by acting as a carbon sinks by helping in $\mathrm{CO}_{2}$ mitigation with the $\mathrm{CO}_{2}$ storage rate per unit area of plantation is four times that of hard wood with higher release of oxygen around $35 \%$ in the atmosphere [5].

Biomass recalcitrance constructed by the chemical compositions of lignocelluloses and their interactions has become a key limiting factor for cheaply releasing sugars from plant cell walls for ethanol production. Thus, lignocellulosic biomass usually should be pretreated to overcome the biomass recalcitrance and increase cellulose digestibility. These pretreatments increase the enzymatic hydrolysis of cellulose by removing hemicelluloses and delignification or modifying the lignin structure to reduce particle size and to increase the porosity of the substrates [6]. Various pretreatment technologies have been developed in recent decades for improving the enzymatic hydrolysis of various woody and non-woody biomass. However, most of the previous studies utilized energy extensive strategies or higher chemical concentration to achieve better delignification of the agricultural lignocellulosic biomass. In the literature, no detailed study was found regarding bamboo biomass utilization in biofuel production. To improve the energy-saving method for the pretreatment and bioconversion of biomass, reducing the high input of chemicals and/or energy is a crucial step. For the successful conversion of agroforestry biomass, therefore, new and more effective process technologies are needed among several alternative pretreatment techniques being investigated. Present study investigated the effect of different physical, chemical and biological methods on bamboo biomass to represent the best delignification methodology in an environment friendly manner. However, comparison of different pretreatment methods was not been well 
investigated yet, especially chemical and biological pretreatment method. Therefore, an innovative methodology is required that enhances the cellulosic fiber content for easy hydrolysis by simultaneously decreasing the lignin cementing. This paper described new lignolytic fungal culture that showed maximum delignification of the bamboo biomass along with alkaline-oxidative treatment and also clearly illustrates the effect of different methods in removal of recalcitrant lignin polymer. Our study also suggested that Bambusa could be a suitable substrate for bio-ethanol industry.

\section{Materials and methods}

\subsection{Preparation of Bamboo Biomass}

Bamboo, a fast growing perennial woody grass, was used as a source of lignocellulosic substrate for its bioconversion into fermentable sugars. Two species of bamboo, Bambusa balcooa and Bambusa nutans were used in this study. Green woody samples of one year old bamboo plants of the two species were collected from agroforestry research center (AFRC), G.B Pant University of Agriculture and Technology, Pantnagar, Uttarakhand. All the selected fresh stem samples were chopped into small pieces and dried in hot air oven at $60 \pm 5^{\circ} \mathrm{C}$ for two weeks till a constant weight was achieved. The dried pieces were then grounded using willey mill into fine powder preparation. The powder was then sieved through $2 \mathrm{~mm}$ diameter sieve and stored in air tight container at $4^{\circ} \mathrm{C}$ till further use. The moisture content in the samples was determined using the formula as given:

$$
\text { Moisture content }=\frac{\text { Fresh weight of wood-Dry weight of wood }}{\text { Fresh weight of wood }} \times 100
$$

\subsection{Chemical analysis of Bamboo Biomass}

In order to select one of the potential bamboo species for further saccahrification process, the powdered wood biomass from the two bamboo species was checked for its cellulose, ash, moisture and lignin contents. The cellulose content in bamboo biomass was estimated by the method of Zhang et al., 2012[7]. The ash, moisture and lignin content analysis was conducted according to ASTM (American Society for Testing and Materials), respectively [8, 9]. Briefly, the powder preparation $(0.5 \mathrm{~g})$ was mixed with $1.25 \%$ solution of $\mathrm{H}_{2} \mathrm{SO}_{4}(150 \mathrm{~mL})$ and boiled for $30 \mathrm{~min}$, followed by 3 washing with hot distilled water. The washed biomass was further boiled for $30 \mathrm{~min}$ in $1.25 \%$ solution of $\mathrm{KOH}(150 \mathrm{~mL})$ and again washed three times with hot distilled water, followed by washing once with cold distilled water and three times again with acetone. It was then dried in oven for $1 \mathrm{~h}$ at $60 \pm 5^{\circ} \mathrm{C}$ and weighed again. The biomass was further heated in muffle furnace at $540^{\circ} \mathrm{C}$ for $5 \mathrm{~h}$. The resulting ash was cooled down and weight taken. The cellulose content was determined using the following equation: 
Cellulose content $(\%)=\frac{F_{1}-F_{2}}{F_{O}} \times 100$

Where, $\mathrm{Fo}_{\mathrm{O}}=$ weight of fresh biomass $(0.5 \mathrm{~g}), \mathrm{F}_{1}=$ weight of dried biomass and $\mathrm{F}_{2}=$ weight of ash.

Briefly, oven dried bamboo wood powder (1.0 g) was mixed with acid detergent solution (100 mL) and boiled for $15 \mathrm{~min}$ continuously and further refluxed for $60 \mathrm{~min}$ on heating mantle. The contents were then filtered using filter paper and washed three-four times with hot distilled water until foam generation stopped. The biomass was then washed thoroughly with acetone till the filtrate was colorless. After the acetone washing, the biomass was dried in oven at $60 \pm 5^{\circ} \mathrm{C}$ till constant weight was reached. The ADF content was determined using the following equation:

$$
\operatorname{ADF}(\%)=\frac{\text { Weight of Acid Detergent Fibre }}{\text { Weight of woodpowder }} \times 100
$$

The dried acid detergent fibre (ADF) was mixed with $72 \% \mathrm{H}_{2} \mathrm{SO}_{4}$ solution $(30 \mathrm{~mL})$ and allowed to stand for $3 \mathrm{~h}$ with intermittent stirring. The solution was then diluted with distilled water $(100 \mathrm{~mL})$ to reduce the consistency of the fibres. The contents were then filtered and washed with distilled water until a clear filtrate was obtained, which was then dried in oven at $60 \pm 5^{\circ} \mathrm{C}$ till a constant weight was reached. The ADL content was determined using the formula as given:

$$
\text { ADL }(\%)=\frac{\text { Weight of Acid Detergent Lignin }}{\text { Weight of wood }} \times 100
$$

The acid detergent lignin (the residue left after acid treatment) was transferred to a muffle furnace and heated at $575^{\circ} \mathrm{C}$ for $3 \mathrm{~h}$. The remaining ash content was calculated using the following formula:

$$
\text { Ash }(\%)=\frac{\text { Weight of Ash }}{\text { Weight of wood }} \times 100
$$

Finally, the lignin content $(\%)$ in the bamboo wood powder was calculated using the formula as given:

$$
\text { Lignin }(\%)=\frac{\text { Acid detergent lignin }- \text { Ash }}{\text { Weight of wood }} \times 100
$$

\subsection{Biomass pretreatment: Delignification process}

On the basis of moisture, cellulose and lignin contents and biomass yield, the bamboo variety Bambusa balcooa was selected for further pretreatment studies. The processed dry bamboo (B. balcooa) powder was subjected to various physical, chemical, physico-chemical, biological and physico-chemical+ biological pre-treatments as described in Table 1 . For biological treatment of the biomass, laccase producing fungal culture Lenzites elegans WDP2 isolated from decaying wood samples, as whole cell catalyst or its laccase enzyme was used. For the production of lignin degrading (laccase) enzyme, the fungal culture was initially grown in laccase production medium $\left(\mathrm{L}^{-1} \mathrm{w} / \mathrm{v}, \mathrm{Glucose}, 3.0 ; \mathrm{KH}_{2} \mathrm{PO}, 5.0\right.$; $\mathrm{NH}_{4} \mathrm{NO}_{3}, 12.5 \mathrm{Mm} ; \mathrm{MgSO}_{4} .7 \mathrm{H}_{2} \mathrm{O}, 1.0$; Tween 20, 0.2; KCl, 0.5; FeSO $4,0.001 ;$ Veratryl Alcohol 1Mm; Trace metal solution, $0.1 \%$ and $\mathrm{pH} 5.0$ ) for $12 \mathrm{~d}$ at $28 \pm 2^{\circ} \mathrm{C}$ [10]. After the incubation period, the culture was centrifuged at $8000 \mathrm{rpm}$ 
$\left(4^{\circ} \mathrm{C}\right)$ for $10 \mathrm{~min}$ and the supernatant was used as a source of crude enzyme. The laccase activity was estimated in the collected supernatant by the method of Karla et al., 2013 [11]. Briefly, a reaction mix was initially prepared containing 1.0 $\mathrm{mL}$ crude enzyme and $3.0 \mathrm{~mL}$ sodium acetate buffer $(10 \mathrm{mM}, \mathrm{pH} 5.5)$ into which $1.0 \mathrm{~mL}$ of guaiacol substrate (2mM) was added. The above solution was mixed thoroughly and incubated at $30^{\circ} \mathrm{C} / 15 \mathrm{~min}$ in a hot water bath. After the incubation, absorbance was measured at $450 \mathrm{~nm}$ against blank containing water $(1 \mathrm{~mL})$ instead of the enzyme source. One unit of laccase enzyme was defined as "the amount of enzyme required to oxidize $1 \mu$ mol of guaiacol in one minute". The laccase activity in $\mathrm{U} / \mathrm{mL}$ was calculated using the formula as given:

Enzyme activity $($ E.A) $(\mathrm{U} / \mathrm{mL})=\mathrm{A} \times \mathrm{V} / \mathrm{t} \times \mathrm{e} \times \mathrm{v}$

E.A= Enzyme activity; $A=$ Absorbance; $V=$ Total mixture volume; v= enzyme volume $(\mathrm{mL})$ $\mathrm{t}=$ incubation time; $\mathrm{e}=$ extinction coefficient for guaiacol $\left(0.6740 \mu \mathrm{M} \mathrm{cm}^{-1}\right)$

\subsection{Analysis of structural changes in B. balcooa}

The structural changes occurring in the bamboo wood powder after the different pretreatments were checked using scanning electron microscopy (SEM) and Fourier Transform Infrared Spectroscopy (FTIR).

\subsubsection{Scanning electron microscopy (SEM)}

The bamboo samples after selected pretreatment process (alkaline, oxidative, alkaline-oxidative, WDP2 whole cell fungal catalyst and alkaline-oxidative + WDP2 whole cell fungal catalyst) that showed highest exposed cellulose content, were analysed for structural changes in the surface through SEM imaging and also compared with the untreated control samples. The samples were initially completely dried in an oven at $60 \pm 2^{\circ} \mathrm{C}$ to remove the moisture content and further processed for SEM imaging. The SEM images were captured at different magnifications using Scanning electron microscope (LEO $435 \mathrm{VP})$.

\subsubsection{Fourier Transform Infrared (FTIR) Spectroscopy}

The selected dried wood samples after certain treatments as mentioned above were also analysed by FTIR spectroscopy for changes in molecular bonding. The FTIR spectra of the treated samples were also compared with those of untreated samples. The spectroscopic analysis was done using Thermo-Nicolet 670 FTIR spectroscope. The changes in peaks were recorded at $4 \mathrm{~cm}^{-1}$ in the wave number region of $400-4000 \mathrm{~cm}^{-1}$.

\subsection{Statistical analysis}


All the experiments were conducted in triplicate and presented as mean \pm standard deviation (SD). The data from pretreatments study were compared by two-way analysis of variance (ANOVA) using Graph pad prism version 8.0 following Dunnett's comparison test at the 5\% probability level $(\mathrm{p}=0.05)$.

\section{Results and Discussion}

\subsection{Selection of potential Bamboo species}

India is the world's second largest producer of bamboo with an average annual production of about 32 million tons. About 5.4 million tons of bamboo residues are generated in the country every year by the bamboo processing industries of which about 3.3 million tons remains as surplus $[12,13]$. In order to select appropriate biomass for efficient bioconversion into fermentable sugars, the biomass should have high biomass yield and cellulose content with low lignin, ash and moisture contents. In this study, the two bamboo species were estimated for various parameters such as biomass yield, cellulose, lignin, ash and moisture contents in order to select the potential bamboo species for further pretreatment studies.

\subsection{Biomass yield and Moisture content}

Plant biomasses with low moisture content and high biomass yield are desirable for the industrial production of bioethanol. The total available amount of organic biomass that can be used for bioenergy production is inversely proportional to the moisture content of the wood. Presence of higher moisture content in the biomass is also not desirable from microbial contamination point of view that can affect the storage stability of the biomass [14]. In this study, higher biomass yield was obtained in the Bambusa balcooa species (14.7 Kg/culm) compared to Bambusa nutans ( $8.52 \mathrm{Kg} / \mathrm{culm})$ as described in Table 2. Further, both the samples were dried in an oven to check the moisture content. The moisture content measured 25.2\% and 22.5\% in the biomass of Bambusa balcooa and Bambusa nutans, respectively. Earlier, lower moisture content at the levels of $14.30 \%$ have also been reported in B. deecheyama species[15]. Although, slight variation in the moisture content was observed between the two species in our study, it was not statistically significant and comparatively less moisture content was obtained in the two species compared to other species.

\subsection{Chemical composition of Biomass}

The dried fine powdered biomass from the two bamboo species was further analyzed for cellulose, ash and lignin contents. In terms of cellulose content, a much higher level was obtained in Bambusa balcooa (44.2\%) as compared to Bambusa nutans (28.2\%). However, not very significant differences were observed in the lignin and ash content between 
the two species of Bambusa balcooa (28.9\% and 0.002\%, respectively) and Bambusa nutans (27.8\% and $0.002 \%$, respectively). Higher cellulose content with low lignin concentration is desirable, which positively correlates with the glucose release during hydrolysis process that is appropriate for biorefinery industries. However, the proportion of chemical components in plant biomasses varies greatly based on the environmental factors, growth conditions and maturity of the plant. The cellulose and lignin content in various bamboo species has been reported to vary from 29.3 to $49.1 \%$ and 23.8 to $26.1 \%$, respectively [16]. Celluloses are approximately $70 \%$ of the total biomass and are strongly connected to lignin by covalent and hydrogen bonds that makes the structure highly resilient and hydrolysis-resistant. This extremely recalcitrant behavior is related to the presence of lignin, the degree of cellulose crystallinity, the degree of polymerization of polysaccharides, the surface area available and the moisture content [17]. In this study, among the other parameters, Bambusa balcooa comparatively showed much higher cellulose content and hence, was selected as lignocellulosic biomass for further saccharification process.

\subsection{Pretreatment of Bambusa balcooa biomass: Delignification process}

The selected Bambusa balcooa biomass further underwent various individual and combinatorial pretreatments to determine the best method that would result in maximum decrease in lignocellulose recalcitrance by decreasing the lignin levels and simultaneously increase the cellulose release.

\subsubsection{Physical treatment}

\section{(a) Autoclaving}

In the first instance, the biomass was subjected to autoclave treatment by exposing to a high pressure under wet conditions for prolonged time period to delignify the biomass. The autoclaving process resulted in a slight increase in the cellulose content to $51.6 \%$ in comparison to control (44.2) along with a slight decrease in lignin content by $21.0 \%$ compared to the control (28.9\%). Steam explosion method was first introduced by Mason, 1926, [18] as a biomass pre-treatment method. This method is suitable for lignin enriched biomass and the efficiency is dependent on pressure, temperature, and reaction time along with the biomass type [19]. The water in itself is not sufficient in breaching the phenolic polymers of lignin, hence unable to interrupt the composite ether bonding of cellulose and lignin. However, a major disadvantage of the steam related method is the high energy requirement. In addition, individual autoclaving treatments do not seem to significantly enhance the delignification of the biomass which has also been reported earlier by Debiagi et al, 2020 [20], who reported 
only a slight increase in cellulose content with a slight decrease in lignin content compared to control when the biomass from wheat bran and oat hulls was exposed to autoclaving.

\section{(b) Liquid hot water treatment}

The method, also known as hot compressed water treatment, is similar to steam pretreatment method but as the name suggests, it uses water at high temperature $\left(100-230^{\circ} \mathrm{C}\right)$. The hot water treatment leads to the hydrolysis of hemicellulose and lignin making cellulose more accessible. The formation of fermentation inhibitors is also avoided at high temperatures [21]. In the present study, liquid hot water pretreatment resulted in a significant increase in cellulosic content $(62.2 \%)$ as compared to $44.2 \%$ cellulose in untreated sample. Similarly, lignin content was also decreased to $19.7 \%$ as compared to $28.9 \%$ in control. Liquid hot water (LHW) pretreatment has emerged as one of the leading pretreatment technologies utilizing no other chemicals apart from water at elevated temperature and pressure. Earlier, steam explosion and hot water have been applied as powerful physical pretreatments in different biomass materials [22]. Here, a cost effective approach using boiling water bath without any external pressure was utilized and under such conditions, significant lignin reduction was achieved that allowed increased cellulose accessibility. At high temperatures, water acts as both a solvent and a catalyst which disrupts the ester and ether bonds that is accompanied by a release of organic acids from biomass which ultimately help in disrupting the cell wall matrix and then releasing the residue of ferulic acid, lignin and carbohydrates [23]. However, due to the requirement of large amount of energy in downstream processing and huge amount of water involved, the technique has not been very useful in industrial applications. In addition, most of the studies by this method have been carried out at higher temperature range $\left(>100^{\circ} \mathrm{C}\right)$ which makes it unsafe and unfit in biorefinery field.

\subsubsection{Chemical pre treatment}

\section{(a) Alkali treatment}

Usually lime (calcium hydroxide) or sodium hydroxide is used in alkaline treatment study. Here, biomass treatment with $\mathrm{NaOH}(2 \% \mathrm{v} / \mathrm{v})$ did not show any significant increase either in exposed cellulosic content $(50.6 \%)$ nor effective decrease in lignin $(24.5 \%)$. Very slight difference was observed in comparison to the untreated biomass. $\mathrm{NaOH}$ penetrates the interface between lignin and polysaccharides, inducing saponification and cleavage of inter-molecular ester bonds to facilitate lignin solubilisation and partial degradation of polysaccharides [24], although, the treatment also remove acetyl and the various uronic acid substitutions on hemicellulose that lowers the accessibility of the enzyme to the hemicellulose 
and cellulose surface [25]. In comparison to this study, somewhat higher removal of lignin $(72.32 \%)$ with the same concentration of $\mathrm{NaOH}(2 \%)$ from lignocellulosic biomass have been reported by earlier workers, however, this was achieved at very much higher temperature [26]. However, the main limitation of this method is the utilization of higher concentration of alkali which require large amount of water to neutralize the residual amount of alkali in the treated biomass, which possibly increase the cost of pretreatment and also affect the hydrolysis process. In view of this problem, the present study utilized lower concentration of $\mathrm{NaOH}$ at moderate reaction temperature, however not very satisfactory result was obtained. Similar to our findings, Zhao et al., 2008[27] have also reported very low impact of mild alkali treatment of $\mathrm{NaOH}$ on different biomass containing less than $26 \%$ lignin viz. wheat straw, switchgrass, hardwoods and softwoods.

\section{(b) Oxidative treatment}

Oxidative treatment involves the treatment of lignocellulosic biomass with oxidizing agents such as $\mathrm{H}_{2} \mathrm{O}_{2}$, ozone, oxygen, air etc., out of which the most commonly used is $\mathrm{H}_{2} \mathrm{O}_{2}$. A number of chemical reactions such as electrophilic substitution, side chain displacements, and oxidative cleavage of aromatic ring ether linkages may occur during oxidative pretreatment. The treatment also does not create any harmful residues unlike other chemical treatments. In the present study with $\mathrm{H}_{2} \mathrm{O}_{2}$ pretreatment, the cellulosic content increased from $44.2 \%$ (in control) to $52.6 \%$ along with decrease in lignin content from $28.2 \%$ (in control) to $22.1 \%$. Earlier, oxidative treatment has been used to degrade lignin content of many lignocellulosic materials such as wheat straw, sugarcane bagasse, peanut, cotton straw, and poplar sawdust [28]. The treatment leads to the oxidation and cleavage of lignin, thereby increasing the accessibility of cellulose for further hydrolysis. Oxidative pretreatment was conducted in three other different combinations with $\mathrm{NaOH}, \mathrm{Fe}$ shavings and $\mathrm{Fe}$ shavings $+\mathrm{NaOH}$. Maximum cellulose recovery was observed in combined treatment of $\mathrm{NaOH}+\mathrm{H}_{2} \mathrm{O}_{2}$ showing increased cellulosic content of $64.8 \%$ with reduced lignin content of $18.7 \%$. Similar results were observed in combined effect of $\mathrm{NaOH}+\mathrm{H}_{2} \mathrm{O}_{2}+\mathrm{Fe}$ shavings with recovery of cellulosic content of $60.4 \%$ and lignin content of $19.5 \%$ while treatment with $\mathrm{H}_{2} \mathrm{O}_{2}+\mathrm{Fe}$ shavings showed the cellulosic content of $54.8 \%$ and lignin content of $21.6 \%$. It has been documented that the metal catalysts by their catalytic activity increases the overall conversion of lignins into degraded products and prevent the accumulation of inhibitory products. All combinations of $\mathrm{H}_{2} \mathrm{O}_{2}$ were showing good effect on bamboo biomass treatment in contrast to only $\mathrm{H}_{2} \mathrm{O}_{2}$ treatment in enhancing cellulose fiber exposer with lignin removal. However, similar to our study, 
not very significant increase in cellulose release have been achieved with $\mathrm{H}_{2} \mathrm{O}_{2}$ treatment alone, rather its combination with other treatments such as metal catalysts (Fe shavings), $\mathrm{NaOH}$ have been observed to show promising results [29].

\section{(c) Nano-catalyst with alkali-peroxide treatment (Titanium Dioxide)}

Certain studies have shown that $\mathrm{TiO}_{2}$ nano-powder catalyst can carry out efficient catalytic degradation of lignin or related compounds [30]. Here, two combinations of $\mathrm{TiO} 2$ with $\mathrm{NaOH}$ and $\mathrm{H}_{2} \mathrm{O}_{2}+\mathrm{NaOH}$ were tested. Maximum cellulose recovery $(60.8 \%)$ and lignin removal $(19.2 \%)$ was observed in case of $\mathrm{TiO}_{2}+\mathrm{NaOH}+\mathrm{H}_{2} \mathrm{O}_{2}$ pre-treatment as compared to $\mathrm{TiO} 2+\mathrm{NaOH}$ combination wherein lesser lignin (20.3\%) removal and cellulose release (56.8\%) was observed. Previously, the combined use of alkali + peroxide has shown to result in a significant improvement in cellulosic fiber recovery up to $77.25 \%$ [31]. However, not many attempts have been made to study the effect of nanoparticles supplementation in the pretreatment of lignocellulosic biomass. Titanium oxide nanoparticle causes regeneration of cellulosic fibers and affects the structure by restricting fibre bundling and thus opens up the cellulose structure for hydrolysis process. Although, the $\mathrm{NaOH}$ and $\mathrm{H}_{2} \mathrm{O}_{2}$ treatment could release more cellulose than the combination with $\mathrm{TiO}_{2}$ nanoparticle, the present attempt also shows that the $\mathrm{TiO}_{2}$ supplementation in certain chemical treatment $(\mathrm{NaOH}$ in this case) could enhance the lignin degradation and increase the availability of cellulosic fibers than the $\mathrm{NaOH}$ alone.

\subsubsection{Biological pre treatment}

In comparison to the conventional chemical and physical pretreatment methods, biological pretreatments are considered more efficient, environmental friendly and low-energy intensive process. Biological pretreatments are normally carried out by microorganisms such as brown, white and soft-rot fungi which mainly degrade lignin and hemicellulose along with a small amount of cellulose. In the present study, the selected bamboo biomass was separately treated with the white rot fungal isolate Lenzites elegans WDP2 as whole cell catalyst as well as by using laccase enzyme from Lenzites elegans WDP2. It was observed that treatment with whole cell fungal culture could result in significant increase in cellulose content $(68.4 \%)$ along with lower levels of lignin content (16.6\%) in contrast to laccase enzyme treatment (cellulose and lignin content of $60.4 \%$ and $18.03 \%$, respectively). The best results as well as the highest enzyme activity from the fungal culture is shown in Fig. 1, was achieved on $10^{\text {th }}$ day of culture incubation during the 12 days of pretreatment study. Here, the enzymatic treatment was found to be not as effective as cell catalyst treatment, which could be due to the use of crude enzyme with low activity (28.44 $\left.\mathrm{UmL}^{-1}\right)$ (analysis not shown), besides in addition to laccases (lignin degrading enzymes), other enzymes such as peroxidises also helps in increased degradation of lignin by white rot fungi [32]. Biological 
pretreatment methods have an advantage over other physical and thermochemical processes in terms of equipment needed and energy consumed. Currently, much of the research have focused on wood rot fungi, which tend to be more potential due to their special oxido-reductive enzyme systems such as laccase in biomass pretreatment process [33]. Bari et al.,2016 [34] reported very high lignin degradation (57.4\%) from beech wood in 120 days of pretreatment time by the usage of Trametes versicolor. Similarly, another study reported $24 \%$ delignification of bamboo culms by Echinodontium taxodii 2538 and Trametes versicolor spp. after 28 days of treatment [35]. Although, the fungi are highly potent for lignin degradation, its application is not feasible for large-scale production due to the long residence period of pretreatment which raises the overall cost of production. However, in this study we could achieve a significant delignification within the early 12 days of incubation with the fungal culture, L. elegans. The effect of all different pretreatment methods on cellulose and lignin content of bamboo biomass is listed in Table 3.

It is apparent that between the different physical, chemical and biological pre-treatments approaches, the best results could be obtained by biological treatment of biomass with whole cell fungal catalyst. Alternatively, chemical treatment with alkaline-peroxide was also found to give satisfactory results, although the effect was not as significant as the biological treatment. As per Huang et al., 2017 and Bhowmick et al., 2018 [36, 37], it is very difficult for a single process to split the lignin and hemicellulose structures and release the cellulose, since the lignocellulose residues have distinctive features, such as the cellulose crystallinity index, degree of polymerization of cellulose, and cellulose insulation by hemicellulose, lignin, and acetyl contents [20]. Hence, the employment of two or more different pretreatments as a combined method is necessary to achieve increased lignin degradation and hemicellulose solubilization then a single method can alone.

\subsection{Combined pre treatment}

\subsubsection{Physical + chemical treatments}

During individual treatment experimentation, alkali-peroxide method had resulted in great deformation of complex phenolic polymer from bamboo biomass, which in turn enhanced the cellulosic part of the substrate. For the efficient treatment of the biomass, alkali-peroxide treatment was combined with autoclaving method to further increase the intensity of delignification. Therefore, in the present study, the biomass was subjected to physical treatment (autoclaving) followed by treatment with alkaline peroxide $\left(\mathrm{NaOH}+\mathrm{H}_{2} \mathrm{O}_{2}\right)$ treatment. An increased cellulose content of $(55.6 \%)$ was noted along with decreased lignin content of $21.1 \%$ as compared to control is described in Table 4 . The significant results 
were not found in contrast to alkaline and peroxide treatment. The very diminutive changes had been observed in case of lignin degradation but the cellulose content of the biomass was slightly increased in contrast to the individual parameters. The disadvantage of the steam related methods is the generation of inhibitory compounds that becomes toxic for further process [38]. The effect of combined methodology in this case was not found as significant if compared to their individual treatment. The reason behind this was not clear but may be the inhibitory compounds released during autoclaving method interfered with the alkali-peroxide treatment and hence became less significant in decreasing the lignin complexity of the biomass.

\subsubsection{Physical + biological treatments}

The bamboo biomass was treated by two different processes i.e. autoclaving with L. elegans as whole cell culture and autoclaving with laccase enzyme separately to study the effect on bamboo delignification. After pretreatment, the cellulose content was found to be $68.5 \%$ and $65.0 \%$ with $20.7 \%$ and $20.8 \%$ of lignin content in both combined whole cell and enzymatic pretreatment method is listed in Table 4, respectively. It was observed that the cellulose content was increased and lignin content was decreased compared to the autoclaving method alone. However, compared to both biological methods, no differences were found in cellulose content with less lignin degradation. Wang et al., 2012 [39], combined biological pretreatment with liquid hot water pretreatment method for better enzymatic saccharification of Populus tormentosa. This combination resulted in highest hemicellulose removal (92.33\%) and resulted in 2.66-fold increase in glucose yield as compared to pretreatment carried out with liquid hot water alone. Similarly, in this research combined effect was found to be significant in contrary to autoclaving alone. It was reported that autoclaving method releases undesirable lignocellulose-derived inhibitors from lignocellulosic substrate which affects the other processes of plant based biomass hydrolysis [38]. In this study, biological method alone was more effective as compared to autoclaving-biological combination. It was concluded that the combined treatment of autoclaving with chemical and biological methods was less significant in breaking lignin polymer from bamboo feedstock.

\subsubsection{Chemical + Biological treatments}

Initially, the biomass was treated with alkaline-peroxide $\left(\mathrm{NaOH}+\mathrm{H}_{2} \mathrm{O}_{2}\right)$ pre-treatment under similar conditions as used in alkaline-peroxide treatment alone. The chemically treated biomass was washed to remove the chemical residues and dried to remove the water content. Then, the biomass was treated with active L. elegans WDP2 culture and laccase enzyme, separately. After both the treatments, the cellulose content increased to $76.6 \%$ and $64.8 \%$ with lignin content decreased to 
14.5\% and $20.5 \%$ as described in Table 4 . The combined effect of alkaline-peroxide treatment followed by L. elegans WDP2 treatment showed great influence in decreasing the recalcitrant-cementing material i.e lignin content of the biomass with maximum release of the cellulosic fibers. Our results are in accordance with those of Yu et al., 2009 [40] who also studied the novel combination of the chemical and biological treatment on the substrate, rice husk. It was reported that the combined pretreatment of rice husk using $2 \% \mathrm{H}_{2} \mathrm{O}_{2}$ along with P. ostreatus was found more effective as compared to single step pretreatment using $P$. ostreatus for 60 days. Lignin removal was also found significantly higher as compared to one step treatment. In case of alkali-peroxide with biological enzymatic treatment, the results were not that significant in terms of decreasing lignin component. This may be due to the ineffectiveness of the enzyme caused by the presence of any chemical residue in the biomass. The other reason may be due to the use of unpurified crude enzyme. In case of biological pretreatments, whole cell culture method was more effective in relation to enzymatic method and showed satisfactory results in combination with alkali-peroxide treatment as best delignification method. The chemical pretreatment conditions were also maintained at low chemical concentration to decrease the effect of harsh chemicals on biological processing of lignolytic fungal system to maximize cellulosic fibers release from complex lignin cementing. From the above results, alkaline oxidative as chemical treatment and L. elegans WDP2 as biological treatment was found to be the best treatment in their combined conditions.

Another approach was also utilized in combined delignification of bamboo biomass in which the substrate was subjected to alkali $(\mathrm{NaOH})$ treatment and further treated with L. elegans WDP2 whole cell culture and laccase enzyme, separately. After the combined treatment, the cellulose content of the biomass was increased to $70.2 \%$ with decreased lignin content of $20.1 \%$. In case of combining enzymatic and $\mathrm{NaOH}$ pre-treatment on the biomass showed virtuous effect in exposing cellulose fibers with total cellulose content of $74.8 \%$ with decreasing the lignin content of the biomass with the total lignin content of $20 \%$ as described in Table 4 . The combined effect of alkali and biological method was found an efficient treatment as compared to the separate methods of alkaline and biological treatment. Previous studies have also found that a combination of another pretreatment process with biological pretreatment process is more effective as compared to a single pretreatment process [19].

\subsubsection{Physical + chemical + biological treatments}

In order to maximize delignification of biomass together with an increase in exposed cellulose content, a combination of physical + chemical + biological pretreatment was given. Two different methods were employed in which biomass was 
first autoclaved and then treated with alkaline-peroxide solution. After these two steps, the pre-treated biomass was further given to biological pre-treatment. In biological method both whole cell treatment and laccase enzyme treatment were treated separately. The higher cellulose release was observed in the case of physical-chemical and biological combined treatment using whole cell culture with $72.6 \%$ cellulose and $19.8 \%$ lignin content. However, in case of enzymatic treatment, only $70.0 \%$ cellulose content with lignin content of $19.9 \%$ was estimated as described in Table 4 .

The overall summary of the combined pre-treatments was that different methods were showing improved effects in contrast to single operated treatments. In all the cases, the cellulose content was increased and lignin content was decreased. Among all methods, the best method was alkaline-peroxide treatment along with fungal treatment using Lenzites elegans WDP2 that showed maximum cellulose exposer with maximum lignin decrement. Percent increase in cellulose and percent decrease in lignin content of the Bambusa balcooa biomass during different pretreatment study is represented in Fig. 2. The combined pre-treatment approach showing agreeable results in enhancing the accessibility of cellobiose polymer (cellulose) and overall phenolic polymer (lignin) degradation from Bambusa balcooa biomass. In addition, direct comparisons between existing pretreatment technologies are difficult due to their dissimilar attributes, as well as the differences in methodology and substrate used.

Lignocellulosic biomass is one of the most abundant resources on this planet which can be extensively exploited in development of second generation fuels. However, the complex structural biology of the plant based substrate restrain the process of generation of bio-fuels. To overcome this problem, various pre-treatment methods have been developed to ease the applicability of the biomass in the hydrolysis process. Hence, the present study attempted to study the effect of different available pre-treatment's (physical, chemical and biological) either individual or their combination on bamboo biomass delignification. All the tested pre-treatments, whether individual or combination, showed significant increase in cellulose and decrease in lignin content. Between the different pre-treatment types, physical pre-treatment methods has advantages of being inexpensive and non-corrosive, however it was observed here that the physical methods were not that efficient especially in breaking down of lignin. At the individual level, the biological treatment using L. elegans WDP2 culture was found as a superior method compared to physical or chemical treatment and was able to comparatively produce higher delignification of phenolic polymer. However, single step pre-treatment methods are considered not that effective in comparison to combined methods in lignin degradation from woody biomass [38] and at present, a combination of physical, chemical and biological methods is employed in delignification of B. balcooa [10]. In this study too, although, single step pre-treatment methods were successful in breaking the lignin polymer structure to a varying 
extent, however the effect was not very significant and satisfactory outcome could only be achieved by combination treatment. Overall, the combination of chemical and biological (alkali-peroxide with L. elegans WDP2) pre-treatment method could produce the best result on the delignification of B. balcooa biomass. The co-effect of alkali-peroxide and biological treatment on bamboo biomass could disperse the ester linkages between hemicelluloses and lignin fibres that may be further degraded by lignin hydrolysing enzymes released from white rot fungus L. elegans WDP2. Earlier, most of the pre-treatment studies have focused on utilizing high concentrations of chemicals in liberating cellulosic fibers from lignin fibres using mostly agricultural waste [41]. Only a few studies have emphasized on the utilization of agroforestry biomass which is released in tones as waste as a possible source of biofuel [15]. In this regard, the current research presents a more efficient and eco-friendly method that employs lesser chemical treatments and uses bamboo as biomass, which could be an effective future source of bioethanol as India houses the second largest bamboo plantation.

\subsection{Monitoring of structural changes in pre-treated bamboo biomass}

Analytical techniques such as FTIR analysis and scanning electron microscopy were used to visualize structural changes caused by pre-treatment in the bamboo biomass.

\subsubsection{Fourier-Transform Infrared Spectroscopy (FTIR)}

FT-IR has been extensively applied in plant cell wall analysis for comparing differences among samples of different ages that undergo developmental and compositional changes in the cell wall. The resulting FT-IR spectrum is a complex fingerprint representing adsorption bands that correspond to the frequencies of vibrations between the bonds of the chemical functional groups comprising the cell wall [2]. In the present study six pre-treated bamboo samples were selected, $\left(\mathrm{H}_{2} \mathrm{O}_{2}\right.$ treated, $\mathrm{NaOH}$ treated, $\mathrm{NaOH}+\mathrm{H}_{2} \mathrm{O}_{2}$ treated, fungal culture treated, $\mathrm{NaOH}+\mathrm{H}_{2} \mathrm{O}_{2}$ with fungal culture treatment and untreated biomass as control. From the above results of pretreatment process, alkali-peroxide and whole fungal cell treatment among different individual methods and alkali-peroxide + whole fungal cell (L.elegans WDP2) from combined treatments were found as best methods in degradation of lignin polymer with maximum cellulose recovery. In the samples treated biomass with $\mathrm{H}_{2} \mathrm{O}_{2}$ or $\mathrm{NaOH}$, changes in wave numbers were observed in the region of 500- 3000 cm-1 that depicts the O-H stretching and C-H stretching in lignin component of the biomass as shown in Fig. 3b, c. In the untreated biomass, a peak at $2269.81 \mathrm{~cm}-1$ was observed but it was not present in the either of the $\mathrm{NaOH}$ or $\mathrm{H}_{2} \mathrm{O}_{2}$ treated samples which indicates breaking of bands leading to lignin degradation in the bamboo samples as shown in Fig. 3a. Slight changes were observed at $1630-1500 \mathrm{~cm}-1$ in both the cases which could be related to the $\mathrm{C}=\mathrm{O}$ stretching 
(unconjugated) and aromatic ring vibration in the lignin component of the biomass. Reduction of bands was observed in the range of 700-1000 cm-1 that attributed to glycosidic linkages and $\mathrm{C}-\mathrm{O}$ vibration in the sample as shown in Fig. $3 \mathrm{~b}$, c. The FTIR spectra of the samples given alkaline-peroxide pre-treatment showed an emergence of new peak at $897.64 \mathrm{~cm}-$ 1 , which is assigned to $\beta$-glycosidic bond in cellulose polymer of the biomass, which was in agreement with the chemical analysis data [42]. A very minute change was observed at $1100 \mathrm{~cm}-1$ wave number which illustrates C-O-C asymmetrical stretching in cellulose and hemicellulose components of the plant biomass. A new peak was observed at $1500 \mathrm{~cm}-1$ that showed aromatic ring vibration in lignin component is shown in Fig. 3d. The results were in accordance with the chemical analysis data, retained the major cellulose content in the alkali-per-oxide pretreated biomass with maximum degradation of lignin aromatic bonding. Earlier, Zheng et al., 2018 [43] have described the FTIR spectrum of wheat straw to analyse the structural changes of various pretreatment. The bands within the range of $1,450-1,630 \mathrm{~cm}-1$ were attributed to the aromatic skeleton stretching vibration, and the intensities of these absorption peaks were stronger in pre-treated samples than those of raw wheat straw. The biomass was also treated biologically using the fungal culture Lenzites elegans WDP2 and by combined treatment (alkaline-peroxide treatment + biological treatment). The FTIR spectra of the biologically treated biomass revealed a new peak at $1731 \mathrm{~cm}-1$ which shows ketone/aldehyde C-O stretching in the hemicellulose or carboxylic groups in lignin. This stretching suggested the breakdown of carboxylic and ester bonds in hemicellulose and lignin from bamboo substrate [44]. The change with broadening of the peak at $3100 \mathrm{~cm}-1$ was clearly revealed in case of combined pretreatment as compared to that of untreated or other chemical treated samples, this relates to the $\mathrm{C}-\mathrm{H}$ and $\mathrm{O}-\mathrm{H}$ bonds stretching. The broad band ranging from 3,000-3,500 $\mathrm{cm}^{-1}$ was assigned to the $\mathrm{O}-\mathrm{H}$ bond stretching. The intensities of these peaks indicated the cellulose content in the pre-treated bamboo samples which is significantly higher in chemical with biological treatment in contrast to other treatment methods. The results of chemical analysis also suggested that the cellulose content in combined treatment method was higher in comparison to other methods. Differences in the biologically treated and chemical + biologically treated samples were also observed in the region of 1600-1650cm-1 which depicts aromatic ring vibration and C-O stretching of the lignin component of the wood as shown in Fig 3e, f. The range of $500-1,770 \mathrm{~cm}^{-1}$ is considered as the lignin fingerprint region. FTIR spectrum of the combined chemical + biological treatment revealed maximum degradation in the lignin component of the biomass with the maximum exposer of cellulosic fibers, which is directly related to the pretreated data, suggesting the best pretreatment process in the delignification of Bambusa substrate. The reference FTIR spectra with absorbance bands indicating hydrolysis in biomass was used to describe the changes in treated and untreated bamboo wood biomass [45, 46]. Fourier 
transform infrared spectroscopy (FTIR) has been used successfully for compositional analysis of lignocellulosic biomass [48].

\subsubsection{Microscopic changes in biomass as revealed by SEM}

Scanning electron microscopy (SEM) is among the powerful tools widely used to investigate the lignocelluloses surfaces [48]. Using SEM, it is possible to see the surface erosions, deconstruction, and re-localization of the cell wall components and to get an idea of the accessibility and the enzymatic hydrolysis improvements [49]. In this study, significant morphological alterations were observed in the pre-treated bamboo powder subjected to various treatments. The untreated bamboo samples revealed rigid and highly ordered stack line fibrils. Its surface was compact and nonporous, which hindered the accessibility of cellulases to cellulose. However, the SEM analysis of the treated samples revealed that after various pre-treatments such as alkaline treatment $(\mathrm{NaOH})$, peroxide treatment $(\mathrm{H} 2 \mathrm{O} 2)$, alkaline peroxide treatment, biological treatment (fungal isolate WDP2) and combined pretreatment using alkaline-oxidative + biological method, the biomass lost its rigidity and compactness as shown in Fig. 4a - 4f. The photomicrographs of all the treated bamboo samples showed appearance of heterogeneous cracks that were scattered throughout the samples. Similar disruption in the lignocellulosic biomass after various treatments has also been well documented by previous workers [50]. Cracks and pit formation is due to the breakdown and removal of large proportion of lignin and hemicellulose and reduction in crystalinity of cellulose after the pre-treatment [51]. The combined treatment showed greater disruption and hydrolysis of the biomass using biological treatment and chemical treatment method and found as a more effective method in causing deformation with disruption of hemicellulose fibres. The co-effect of both the methods resulted in the disconnection of the fibers with the appearance of the pores on the surface of the substrate, which could reduce the structural barrier and assist enzyme accessibility by increasing the surface area. These results are consistent with the FTIR spectra results. The employing of different treatment methods on biomass increases the accessibility of the cellulose for effective hydrolysis. The surface characterization through SEM, revealed the deformation of the biomass which directly related to the breaking of lignin cementing and hemicellulose mesh over the cellulose fibers. Although, the significant changes were observed through FTIR and surface morphology analysis which clearly exposed the breaking of biomass compactness, hence further analysis was not required for lignin wall degradation.

\section{Conclusions}


The present research attempts to provide a broad analysis of the various pretreatment processes on Bmabusa balcooa. The results of all pre-treatment methods show improvement in cellulose exposer for further better hydrolysis reactions. Mean while, the combined alkali-oxidative with fungal WDP2 treatment was found as a promising methodology which demonstrated efficient delignification with highest cellulosic content. Alkaline-oxidative process majorly differs in terms of their selectivity towards removing lignin content. Although, co-effect with lignolytic WDP2 fungal isolate, further improves in catalyzing the remaining phenolic content in lignin polymer to break the lignin cementing. The mild chemicals in the present pretreatment technologies also improve the efficiency of overall technique without deteriorating the environment. In addition, the use of potential white rot fungal system in lignin degradation of agroforestry waste gives us sustainable approach which makes the process efficient and more cost effective in comparison to other pretreatment methods. This research presented a novel method of pretreatment by combining chemical and biological method for the hydrolysis of lignin from the bamboo biomass. And also focuses on bamboo as a sustainable source for biofuel processing that affect the economy of the country.

Author Contributions: Conceptualization, methodology, statistical validation, H.P., L.T.; formal analysis, investigation, data curation, H.P.; writing-original draft preparation, writing- review and editing H.P., L.T., D.P., P.C.; supervision, funding acquisition, L.T. All authors have read and agreed to the manuscript.

Funding: This research received no external funding.

Acknowledgement: The authors are grateful to the director experiment station, G.B Pant University of Agriculture and Technology, Pantnagar, India for providing financial support and necessary research facilities.

Disclosure statement: All the authors declare that they have no conflict of interest in the publication

\section{References}

1. Moe, S.T.; Janga, K.K.; Hertzberg, T.; Hägg, M.B.; Øyaas, K.; Dyrset, N. Saccharification of lignocellulosic biomass for biofuel and biorefinery applications A renaissance for the concentrated acid hydrolysis?. Energy Procedia. 2012, 20, $50-58$.

2. Foston, M.; Ragauskas, A.J. Biomass Characterization: Recent Progress in Understanding Biomass Recalcitrance. Ind. Biotechnol. 2012, 8, 191-208. 
3. Nirala, D.P.; Ambasta, N.; Kumari, P. A review on distribution of bamboos. Life Sciences Leaflets. 2017, 92, 70-78.

4. Biswas, S. Studies on bamboo distribution in North-eastern region of India. Indian Forester. 1988, 114, 514-531.

5.Southern Metropolis Daily Mark. Bamboo: An ultimate green material. 2012. http://gcontent.oeeee.com/8/18/818f4654ed39a1c1/Blog/df2/752aa2.html.

6. Wu, R.; Zhao, X.; Liu, D. Structural features of formaline pretreated sugar cane baggase and their impact on the enzymatic hydrolysis of cellulose. ACS sustain chem eng. 2016, 4, 1255-1261.

7.Zhang, M.; Song, X.; Sun, X.; Wang, Z.; Li, Z.; Ji, H.; Li, J. The relationship between cellulose content and the contents of sugars and minerals during fiber development in colored cotton cultivars. Cellulose. 2012, 19.

8. Sluiter, A.; Hames, B.; Ruiz, R.O.; Scarlata, C.; Sluiter, J.; Templeton, D. Determination of Ash in Biomass. Available online: https://www.nrel.gov/docs/gen/fy08/42622.pdf

9. Sluiter, A.; Ruiz, R.O.; Scarlata, C.; Sluiter, J.; Templeton, D. Determination of Extractives in Biomass. Available online: https://www.nrel.gov/docs/gen/fy08/42619.pdf

10. Pandey, R.K.; Chand, K.; Tewari, L. Solid state fermentation and crude cellulase based bioconversion of potential bamboo biomass to reducing sugar for bioenergy production. J. Sci. Food Agric. 2018, 98, 4411-4419.

11. Kalra, K.; Chauhan, R.; Shavez, M.; Sachdeva, S. Isolation of laccase producing Trichoderma sp. and effect of pH and temperature on its activity. Int. J. Chem tech Res. 2013, 5, 2229-2235.

12.Pandey, A.; Biswas, S.; Sukumaran, R.K.; Kaushik, N. Study on availability of Indian biomass resources for exploitation, a report based on a nation-wise survey. New Delhi: TIFAC, 2009.

13.Sukumaran, R.K.; Surender, V.J.; Sindhu, R.; Binod, P.; Janu, K.U.; Sajna, K.V. Lignocellulosic ethanol in India: Prospects, challenges and feedstock availability. Bioresour Technol. 2010, 101, 4826- 33.

14. Bassam, N. Energy plant species: their use and impact on environment and development. James \& James, London, UK, 1998.

15. Truong, A.H.; Le, T.M.A. Overview of bamboo biomass for energy production, 2014, <halshs01100209>.

16. Higuchi, H. Biochemical studies of lignin formation, III. Physiologia Plantarum, 1957, 10, 633-648

17. Michelin, M.; Ruiz, H.A.; Silva, D.P.; Ruzene, D.S.; Teixeira, J.A.; Polizeli, M.L.T.M. Cellulose from Lignocellulosic Waste. Polysaccharides, 2014, 1-33.

18. Mason, W.H. Process and apparatus for disintegration of wood and the like. US Patent: 1578609, 1926. 
19. Kumar, A.K.; Sharma, S. Recent updates on different methods of pretreatment of lignocellulosic feedstocks :a review. Bioresour. Bioprocess, 2017, 4, 7.

20.Debiagi, F.; Madeira, T.B.; Nixdorf, S.L.; Mali, S. Pretreatment Efficiency Using Autoclave High-Pressure Steam and Ultrasonication in Sugar Production from Liquid Hydrolysates and Access to the Residual Solid Fractions of Wheat Bran and Oat Hulls. Appl. Biochem. Biotechnol. 2020, 190, 166-181.

21. Yang, B.; Wyman, C.E. Effect of xylan and lignin removal by batch and flow through pretreatment on enzymatic digestibility of corn stover cellulose. Biotechnol Bioeng, 2004, 86, 88-95.

22. Studer, M.H.; Demartini, J.D.; Davis, M.F.; Sykes, R.W.; Keller, M.; Tuskan, G.A. Lignin content in natural Populus variants affects sugar release. Proc Natl Acad Sci. 2011, 108, 6300-6305.

23.Zhuang X.; Wang, W.; Yu, Q.; Qi, W.; Wang, Q.; Tan, X.; Zhou, G.; Yuan, Z. Liquid hot water pretreatment of lignocellulosic biomass for bioethanol production accompanying with high valuable products. Bioresour. Technol. 2016, 199, 68-75.

24.Obeng, A.K.; Premjet, D.; Premjet, S. Combining Autoclaving with Mild Alkaline Solution as a Pretreatment Technique to Enhance Glucose Recovery from the Invasive Weed Chloris barbata. Biomolecules. 2019, 9, 120.

25.Chang, V.S.; Holtzapple, M.T. Fundamental factors affecting biomass enzymatic reactivity. Appl. Biochem. Biotechnol. 2000, 5, 84-86.

26.Wang, Z.; Keshwani, D.R.; Redding, A.P.; Cheng, J.J. Sodium hydroxide pretreatment and enzymatic hydrolysis of coastal Bermuda grass. Bioresour. Technol. 2010, 101, 3583-3585.

27.Zhao, Y.; Wang, Y.; Zhu, J.Y.; Ragauskas, A.; Deng, Y. Enhanced enzymatic hydrolysis of spruce by alkaline pretreatment at low temperature. Biotechnol. Bioeng. 2008, 99, 1320-1328.

28. Kumar, P.; Barrett, D.M.; Delwiche, M.J.; Stroeve, P. Methods for pretreatment of lignocellulosic biomass for efficient hydrolysis and biofuel production. Ind. Eng. Chem. Res. 2009, 48, 3713-3729.

29.Cao, W.; Sun, C.; Liu, R.; Yin, R.; Wu, X. Comparison of the effects of five pretreatment methods on enhancing the enzymatic digestibility and ethanol production from sweet sorghum bagasse. Bioresour. Technol. 2012, 111, $215-22$.

30.Kansal, S.K.; Singh, M.; Sud, D. Studies on $\mathrm{TiO}_{2} / \mathrm{ZnO}$ photocatalysed degradation of lignin. J. Hazard. Mater. 2008, $153,412-417$.

31.Diaz, A.; Toullec, J.L.; Blandino, A.; Ory, I.D.; Caro, I. Pretreatment of rice hulls with alkaline peroxide to enhance enzyme hydrolysis for ethanol production. Chem. Eng. Trans. 2013, 32, 949-954. 
32. Vats, S.; Maurya, D.P.; Shaimoon, M.; Negi, S. Development of a microbial consortium for the production of blend enzymes for the hydrolysis of agricultural waste into sugars. J Sci Ind Res. 2013, 72, 585-590.

33.Pandey, R.K.; Tewari, S.; Tewari, L. Lignolytic mushroom Lenzites elegans WDP2: Laccase production, characterization, and bioremediation of synthetic dyes. Ecotoxicol. Environmen Saf. 2018, 158, 50-58.

34.Bari, E.; Reza, H.; Reza, H.; Schmidt, O.; Ohno, K.M.; Clausen, C.A.; Suhaimi, E. Assessing the destructive behaviors of two white-rot fungi on beech wood. Int. Biodeterior. Biodegrad. 2016, 114, 129-140.

35. Tsegaye, B.; Balomajumder, C.; Roy, P. Microbial delignification and hydrolysis of lignocellulosic biomass to enhance biofuel production: an overview and future prospect. Bulletin of the National Research Centre. $2019,43$.

36.Huang, W.; Wang, E.; Chang, J.; Wang, P.; Yin, Q.; Liu, C.; Zhu, Q.; Lu, F. Effect of physicochemical pretreatments and enzymatic hydrolysis on corn straw degradation and reducing sugar yield. BioResource. 2017, 12, 7002-7015.

37. Bhowmick, G.D.; Sarmah, A.K.; Sen, R. Lignocellulosic biorefinery as a model for sustainable development of biofuels and value added products. Bioresour. Technol. 2018, 247, 1144-1154.

38. Baruah, J.; Nath, BK.; Sharma, R.; Kumar, S.; Deka, R.C.; Baruah, D.C.; Kalita, E. Recent Trends in the Pretreatment of Lignocellulosic Biomass for Value-Added Products. Front. Energy Res. 2018, 6.

39.Wang, W.; Yuan, T.; Wang, K.; Cui, B.; Dai, Y. Combination of biological pretreatment with liquid hot water pretreatment to enhance enzymatic hydrolysis of Populus tomentosa. Bioresour. Technol. 2012, 107, $282-286$.

40.Yu, J.; Zhang, J.; He, J.; Liu, Z.; Yu, Z. Combinations of mild physical or chemical pretreatment with biological pretreatment for enzymatic hydrolysis of rice hull. Bioresour. Technol. 2009, 100, 903-908. doi: 10.1016/j.biortech.2008.07.025.

41. Bhatt, S.M.; Shilpa. Lignocellulosic feedstock conversion, inhibitor detoxification and cellulosic hydrolysis - a review. Biofuels. 2014, 5, 633-649.

42.Zhang, H.; Huang, S.; Wei, W.; Zhang, J.; Xie, J. Investigation of alkaline hydrogen peroxide pretreatment and Tween 80 to enhance enzymatic hydrolysis of sugarcane bagasse. Biotechnol. Biofuels. 2019, 12, 107.

43.Zheng, Q.; Zhou, T.; Wang, Y.; Cao, X.; Wu, S.; Zhao, M.; Wang, H.; Xu, M.; Zheng, B.; Zheng, J.; Guan, X. Pretreatment of wheat straw leads to structural changes and improved enzymatic hydrolysis. Sci. Rep. $2018,8,1321$.

44.Phitsuwan, P.; Sakka, K.; Ratanakhanokchai, K. Structural changes and enzymatic response of Napier grass (Pennisetum purpureum) stem induced by alkaline pretreatment. Bioresour. Technol. 2016, 218, $247-256$. 
45. Kline, L.M.; Hayes, D.G.; Womac, A.R.; Labbe, N. Simplified determination of lignin content in hard and soft woods via UV-spectrophotometric analysis of biomass dissolved in ionic liquids Bioresources. 2010, 5, 1366-1383.

46.Xu, F.; Yu, J.; Tesso, T.; Dowell, F.; Wang, D. Qualitative and quantitative analysis of lignocellulosic biomass using infrared techniques: a mini-review. Applied Energy. 2013, 104, 801-809.

47.Saini, J.K.; Saini, R.; Tewari, L. Lignocellulosic agriculture wastes as biomass feedstocks for second-generation bioethanol production: concepts and recent developments. 3 Biotech. 2015, 5, 337-353.

48. Amiri, H.; Karimi, K. Improvement of acetone, butanol, and ethanol production from woody biomass by using organosolv pretreatment. Bioprocess Biosyst. Eng. 2015, 38, 1959-1972.

49.Donohoe, B.S.; Vinzant, T.B.; Elander, R.T.; Pallapolu, V.R.; Lee, Y.Y.; Garlock, R.J.; Balan, V.; Dale, B.E.; Kim, Y.; Moiser, N. S.; Ladisch, M. R.; Falls, M.; Holtzapple, M. T.; Sierra-Ramirez, R.; Shi, J.; Ebrik, M. A.; Redmond, T.; Yang, B.; Wyman, C.E.; Hames, B.; Thomas, S.; Warner, R. E. Surface and ultrastructural characterization of raw and pretreated switchgrass. Bioresour. Technol. 2011, 102, 11097-11104.

50.Shafiei, M.; Karimi, K.; Zilouei, H.; Taherzadeh, M.J. Enhanced ethanol and biogas production from pinewood by NMMO pretreatment and detailed biomass analysis. Biomed research international. 2014, 10.

51.Kumar, S.; Gupta, R.; Lee, Y.Y.; Gupta, R. B. Cellulose treatment in subcritical water: effect of temperature on molecular structure and enzymatic reactivity. Bioresour. Technol. 2010, 101, 1337-1347.

Fig 


\section{Figure Caption:}

Fig. 1. Laccase activity of the fungal culture Lenzites elegans WDP2 during biological pretreatment. (a) brown zone of guaiacol oxidation through laccase catalysis, (b) laccase activity $\left(28.44 \mathrm{UmL}^{-1}\right)$ quantification against clear blank.

Fig 2. Percent increase in cellulose and percent decrease in lignin content of the Bambusa balcooa biomass during pretreatment study. (a) Individual effect of different treatments, (b) combined effect of different treatment methods.

Fig 3. Fourier Transform Infra-red (FTIR) spectra of pre-treated Bambusa balcooa samples (a) untreated, (b) hydrogen peroxide $\left(\mathrm{H}_{2} \mathrm{O}_{2}\right)$ treatment, (c) alkali $(\mathrm{NaOH})$ treatment, (d) alkaline-oxidative $\left(\mathrm{NaOH}-\mathrm{H}_{2} \mathrm{O}_{2}\right)$ pretreatment, (e) biological treatment (L.elegans WDP2 ) and (f) alkaline-oxidative + biological treatment.

Fig 4. Scanning electron photomicrographs of chemically treated Bambusa balcooa wood powder showing hydrolytic breakdowns and topological changes at 1000X : untreated biomass (a), $\mathrm{H}_{2} \mathrm{O}_{2}$ treated biomass (b), $\mathrm{NaOH}$ treated biomass (c), alkaline-oxidative treated biomass (d), biologically treated biomass (e) and biologically + chemically treated biomass (f). 


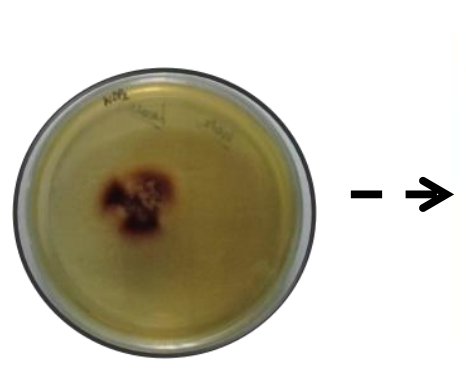

(a)

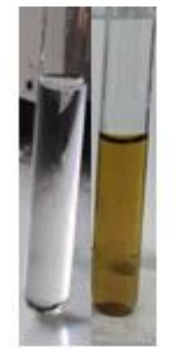

(b)

Figure. 1 Laccase activity of the fungal culture Lenzites elegans WDP2 during biological pretreatment. (a) brown zone of guaiacol oxidation through laccase catalysis and (b) laccase activity (28.44 $\mathrm{UmL}^{-1}$ ) quantification against clear blank. 

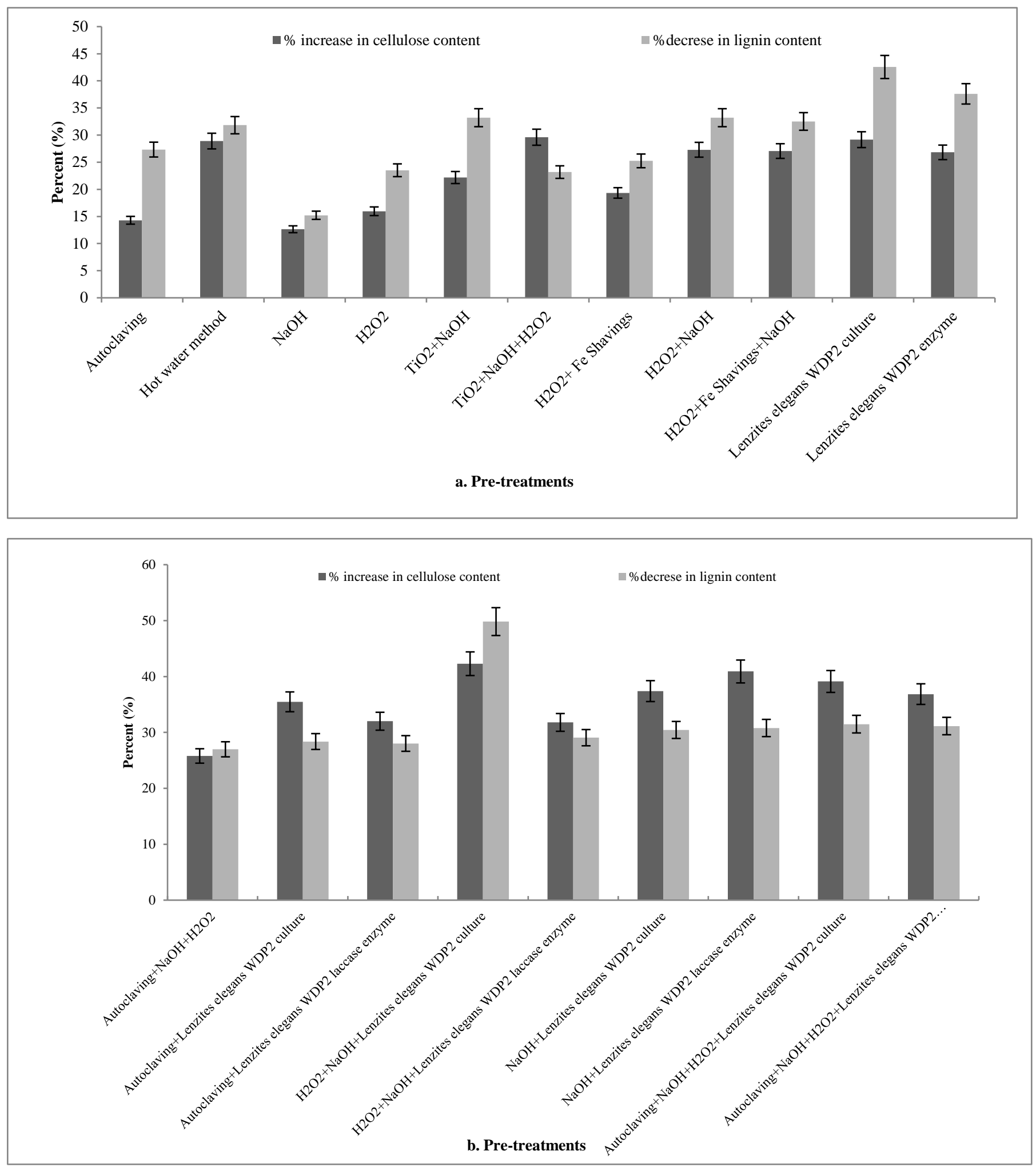

Figure 2. Percent increase in cellulose and percent decrease in lignin content of the Bambusa balcooa biomass during pretreatment study. (a) Individual effect of different treatments, (b) combined effect of different treatment methods. 

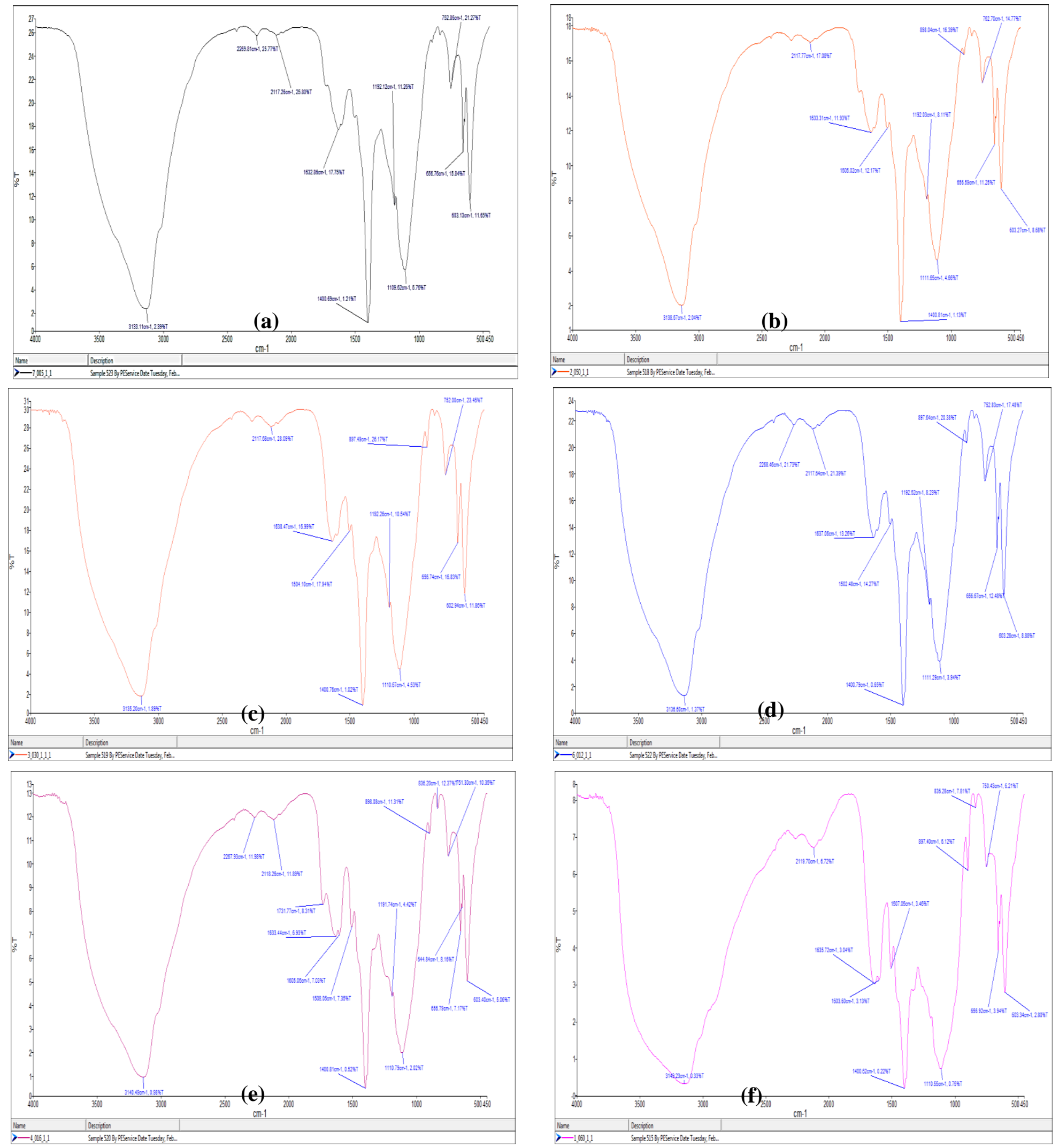

Figu Figure. 3 Fourier Transform Infra-red (FTIR) spectra of pre-treated Bambusa balcooa samples (a) untreated, (b) hydrogen peroxide $\left(\mathrm{H}_{2} \mathrm{O}_{2}\right)$ treatment, (c) alkali $(\mathrm{NaOH})$ treatment, (d) alkaline-oxidative $\left(\mathrm{NaOH}-\mathrm{H}_{2} \mathrm{O}_{2}\right)$ pretreatment, (e) biological treatment (L.elegans WDP2 )and (f) alkaline-oxidative + biological treatment. 


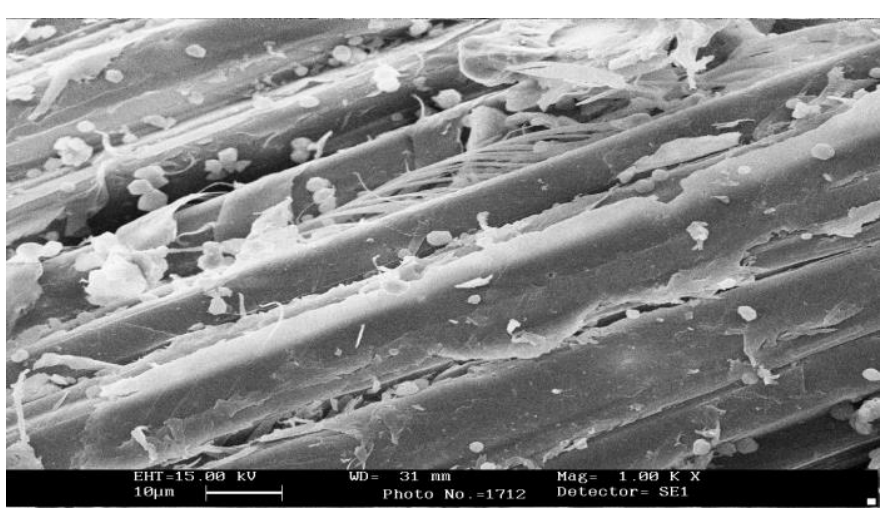

(a)

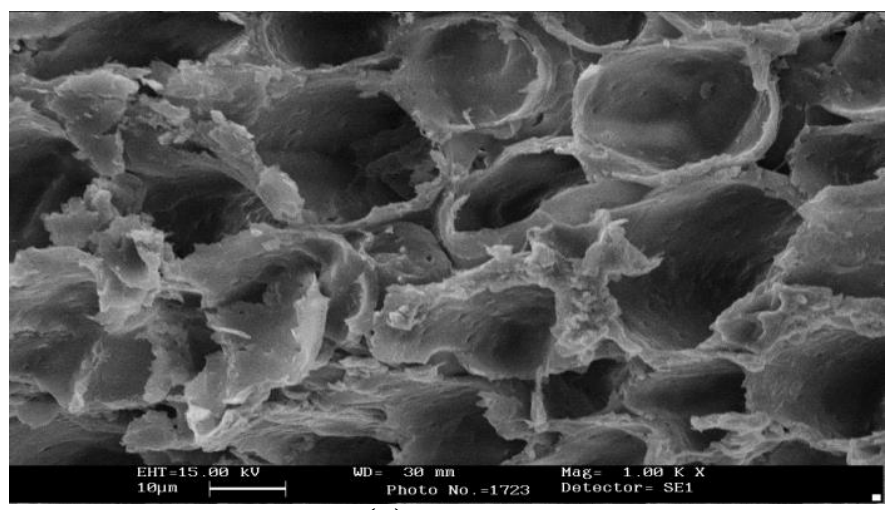

(c)

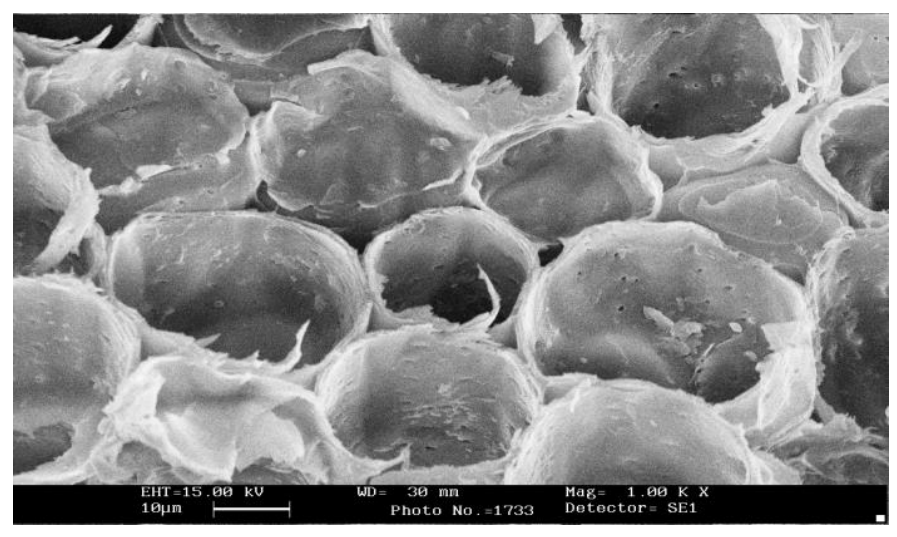

(e)

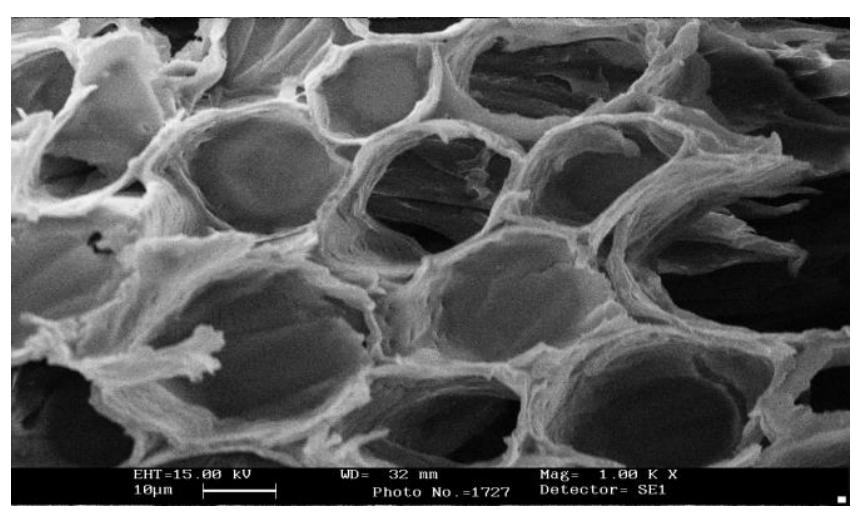

(b)

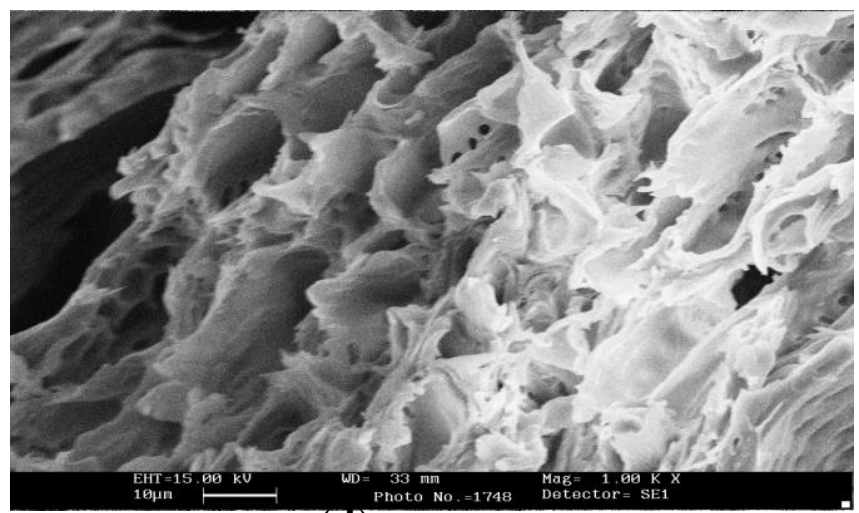

(d)

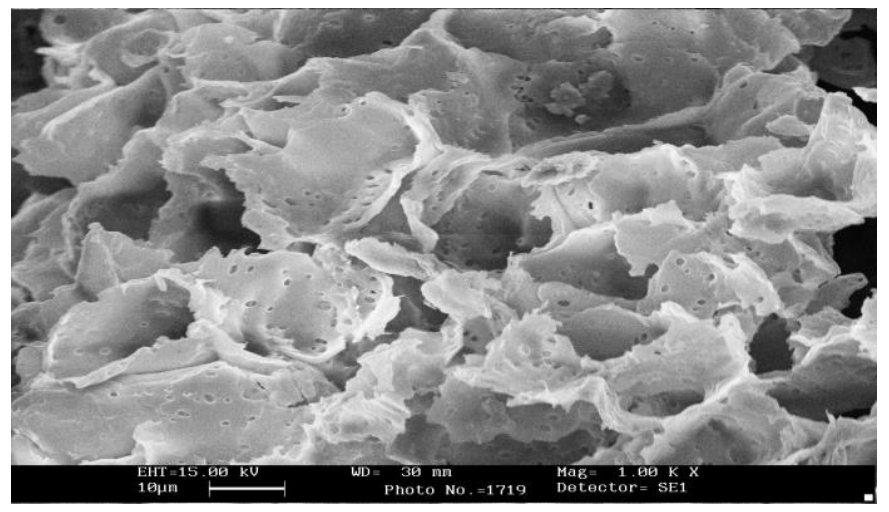

(f)

Figure 4. Scanning electron photomicrographs of chemically treated Bambusa balcooa wood powder showing hydrolytic breakdowns and topological changes at 1000X : untreated biomass (a), $\mathrm{H}_{2} \mathrm{O}_{2}$ treated biomass (b), $\mathrm{NaOH}$ treated biomass (c), alkaline-oxidative treated biomass (d), biologically treated biomass (e) and biologically + chemically treated biomass (f). 
Table 1. Summary of various physical, chemical and biological pre-treatments used for delignification of the woody biomass from the selected bamboo sp. (Bambusa balcooa)*

\begin{tabular}{|c|c|c|c|c|c|c|c|}
\hline $\begin{array}{l}\text { S. } \\
\text { No. }\end{array}$ & *Physical & *Chemical & Biological & $\begin{array}{l}\text { Physico- } \\
\text { chemical }\end{array}$ & \begin{tabular}{|l|} 
Physico-biological \\
\end{tabular} & Chemi- biological & \begin{tabular}{|l} 
Phy-Che-Bio \\
\end{tabular} \\
\hline 1. & ${ }^{2}$ Autoclaving & $\mathrm{NaOH}$ & \begin{tabular}{l}
\multicolumn{2}{l}{ *Lenzites } \\
elegansWDP2 \\
whole cell \\
catalyst
\end{tabular} & $\begin{array}{l}\mathrm{NaOH}+ \\
\text { Autoclaving }+\mathrm{H}_{2} \\
\mathrm{O}_{2}\end{array}$ & $\begin{array}{l}\text { Autoclaving+ } \\
\text { Lenzites } \\
\text { elegansWDP2 } \\
\text { Culture } \\
\end{array}$ & $\begin{array}{l}\mathrm{H}_{2} \mathrm{O}_{2}+\mathrm{NaOH}+\text { Lenzites } \\
\text { elegans } \mathrm{WDP} 2 \text { culture }\end{array}$ & $\begin{array}{l}\mathrm{H} 2 \mathrm{O} 2+\mathrm{NaOH}+\text { Autoclaving+Lenzite } \\
\text { s elegans } \mathrm{WDP} 2 \text { culture }\end{array}$ \\
\hline 2. & $\begin{array}{l}{ }^{\mathrm{b}} \mathrm{Hot} \\
\text { method }\end{array}$ & $\mathrm{H}_{2} \mathrm{O}_{2}$ & $\begin{array}{l}\text { Lenzites } \\
\text { elegansWDP2 } \\
\text { laccase enzyme }\end{array}$ & - & $\begin{array}{l}\text { Autoclaving+ } \\
\text { Lenzites } \\
\text { elegansWDP2 } \\
\text { enzyme }\end{array}$ & $\begin{array}{l}\mathrm{H}_{2} \mathrm{O}_{2}+\mathrm{NaOH}+\quad \text { Lenzites } \\
\text { elegans } \mathrm{WDP} 2 \text { enzyme }\end{array}$ & $\begin{array}{l}\mathrm{H} 2 \mathrm{O} 2+\mathrm{NaOH}+\text { Autoclaving } \\
+ \text { Lenzites elegans } \mathrm{WDP} 2 \mathrm{enzyme}\end{array}$ \\
\hline 3. & - & $\mathrm{TiO}_{2}+\mathrm{NaOH}$ & - & - & - & $\begin{array}{l}\mathrm{NaOH}+ \\
\text { elegansWDP2 Culture }\end{array}$ & - \\
\hline 4. & - & $\begin{array}{l}\mathrm{TiO}_{2}+\mathrm{NaOH}+ \\
\mathrm{H}_{2} \mathrm{O}_{2} \\
\end{array}$ & - & - & - & $\begin{array}{l}\mathrm{NaOH}+ \\
\text { elegansWDP2 enzyme }\end{array}$ & - \\
\hline 5. & - & $\mathrm{H}_{2} \mathrm{O}_{2}+\mathrm{Fe}$ Shavings & - & - & - & - & - \\
\hline 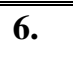 & - & $\mathrm{H}_{2} \mathrm{O}_{2}+\mathrm{NaOH}$ & - & - & 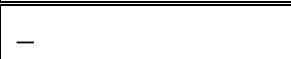 & - & 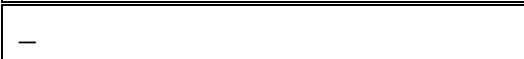 \\
\hline 7. & - & $\begin{array}{ll}\mathrm{H}_{2} \mathrm{O}_{2}+\mathrm{Fe} & \text { Shavings }+ \\
\mathrm{NaOH} & \end{array}$ & - & - & - & - & - \\
\hline
\end{tabular}

* Physical treatments: a wet powdery biomass $(2 \mathrm{gm})$ was heated in an autoclave for $1 \mathrm{~h}$ at $121^{\circ} \mathrm{C}(15 \mathrm{lbpsi})$; ${ }^{\mathrm{b}}$ wet powdery biomass was given hot water treatment in water bath at $100^{\circ} \mathrm{C}$ for $30 \mathrm{~min}$

*Chemical treatments : the dry powdery biomass adjusted with moisture content in the ratio of 1:15 (solid: liquid ratio) was treated with any one of the chemical agents at a time as per details given: (i) $\mathrm{NaOH}(2 \%)$, (ii) $\mathrm{H}_{2} \mathrm{O}_{2}(1 \%)$, (iii) $\mathrm{Fe}$ shavings $(0.5 \mathrm{gm})$ or (iv) $\mathrm{TiO}_{2}(0.2 \%)$ at $80^{\circ} \mathrm{C}$ for $1 \mathrm{~h}$ in hot air oven

*Biological treatment: the sterilized wet biomass (2 gm) was treated with WDP2 fungal culture as biological catalyst (5 plugs) or $5 \mathrm{~mL}$ of crude laccase enzyme solution (28.44
$\mathrm{U} \quad \mathrm{mL}^{-1}$
from
the
same
fungal
culture
using laccase
medium
adjusted with
(1:7)
solid: liquid
ratio. 
Table 2. Lignocellulosic, ash and moisture contents of the green woody biomass from one year old plants 2 of two Bambusa sp.

3

4

\begin{tabular}{|c|c|c|c|c|c|}
\hline Biomass sp. & $\begin{array}{l}\text { Cellulose } \\
(\%)\end{array}$ & Lignin (\%) & Biomass (kg) & Ash (\%) & $\begin{array}{l}\text { Moisture } \\
\text { content }(\%)\end{array}$ \\
\hline Bambusa balcooa & $44.2 \pm 2.15$ & $28.9 \pm 2.26$ & $14.7 \pm 1.49$ & $0.002 \pm 0.001$ & $25.2 \pm 2.73$ \\
\hline Bambusa nutans & $28.2 \pm 2.45$ & $27.8 \pm 2.39$ & $8.52 \pm 1.40$ & $0.002 \pm 0.001$ & $22.5 \pm 0.86$ \\
\hline SEm \pm & 1.33 & 1.34 & 0.834 & 0.0004 & 1.16 \\
\hline $\mathrm{CD}(5 \%)$ & 5.20 & 5.24 & 3.26 & 0.0018 & 4.57 \\
\hline
\end{tabular}

5 *SEm: standard error of mean, CD: critical difference at 5\% $(\mathrm{p}<0.05)$, P level less than 0.05 indicates that the values are 6 significant.

7

8

9

10

11

12

13

14

15

16

17

18 
Table 3. Influence of different pre-treatment methods on the lignin and cellulosic contents of the woody biomass of one year old Bambusa balcooa

21

\begin{tabular}{|c|c|c|c|}
\hline S. No. & Treatments & $\begin{array}{l}\text { Exposed } \\
\text { cellulose } \\
\text { content } \\
(\%, w / w) \\
\end{array}$ & $\begin{array}{l}\text { Lignin content } \\
(\%, w / w)\end{array}$ \\
\hline I. & \multicolumn{3}{|l|}{ Physical pre-treatments } \\
\hline$\overline{\mathbf{i}}$ & Autoclaving & $51.6 \pm 1.49 * * * *$ & $21.0 \pm 0.63 * * * * 25$ \\
\hline ii & Hot water method & $62.2 \pm 2.11 * * * *$ & $19.7 \pm 0.62 * * * * *^{26}$ \\
\hline II. & \multicolumn{3}{|l|}{ Chemical treatments } \\
\hline & & & 28 \\
\hline$\overline{\mathbf{i}}$ & $\mathrm{NaOH}$ & $50.6 \pm 1.35 * * * *$ & $24.5 \pm 0.47 * *$ \\
\hline iii & $\mathrm{H}_{2} \mathrm{O}_{2}$ & $52.6 \pm 1.14 * * * *$ & $22.1 \pm 0.23 * * * * 30$ \\
\hline$\overline{\text { iiii }}$ & $\mathrm{TiO}_{2}+\mathrm{NaOH}$ & $56.8 \pm 0.71 * * * *$ & $20.3 \pm 1.10 * * * * 31$ \\
\hline$\overline{\text { iv }}$ & $\mathrm{TiO}_{2}+\mathrm{NaOH}+\mathrm{H}_{2} \mathrm{O}_{2}$ & $60.8 \pm 0.96 * * * *$ & $19.2 \pm 0.55 * * * * 32$ \\
\hline$\overline{\mathbf{v}}$ & $\mathrm{H}_{2} \mathrm{O}_{2}+\mathrm{Fe}$ Shavings & $54.8 \pm 2.38 * * * *$ & $21.6 \pm 0.42 * * * *$ \\
\hline & & & 34 \\
\hline vi & $\mathrm{H}_{2} \mathrm{O}_{2}+\mathrm{NaOH}$ & $64.8 \pm 1.35 * * * *$ & $18.7 \pm 0.22 * * * *$ \\
\hline vii & $\mathrm{H}_{2} \mathrm{O}_{2}+\mathrm{Fe}$ Shavings $+\mathrm{NaOH}$ & $60.6 \pm 2.82 * * * *$ & $19.5 \pm 0.30 * * * * 36$ \\
\hline III. & \multicolumn{3}{|l|}{ Biological treatments } \\
\hline$\overline{\mathbf{i}}$ & Lenzites elegans WDP2 Culture & $68.4 \pm 1.16 * * * *$ & $16.6 \pm 1.65 * * * * 38$ \\
\hline$\overline{\text { ii }}$ & Lenzites elegansWDP2 enzyme & $60.4 \pm 1.03 * * * *$ & $18.03 \pm 1.44 * * * *$ \\
\hline & & & 40 \\
\hline$\overline{I I V}$ & Control (untreated) & $44.2 \pm 2.15$ & $28.9 \pm 2.26$ \\
\hline $\begin{array}{l}\mathrm{SEm} \pm \\
\mathrm{CD}(5 \%)\end{array}$ & & $\begin{array}{l}0.823 \\
2.40\end{array}$ & $\begin{array}{l}0.573 \\
1.67\end{array}$ \\
\hline
\end{tabular}


Table 4. Combined influence of physical, chemical and biological pre-treatment on lignin and cellulosic contents of the woody biomass of Bambusa balcooa

\begin{tabular}{|c|c|c|c|}
\hline S. No. & Treatments & $\begin{array}{l}\text { Cellulose } \\
\text { content } \\
(\%, w / w)\end{array}$ & $\begin{array}{l}\text { Lignin content } \\
(\%, w / w)\end{array}$ \\
\hline I. & \multicolumn{3}{|l|}{ Physical + chemical treatments } \\
\hline$\overline{\mathbf{i}}$ & בAutoclaving $+\mathrm{NaOH}+\mathrm{H}_{2} \mathrm{O}_{2}$ & $55.6 \pm 2.57 * * * *$ & $21.1 \pm 0.55 * * * *$ \\
\hline II. & \multicolumn{3}{|l|}{ Physical + biological treatments } \\
\hline$\overline{\mathbf{i}}$ & $\begin{array}{l}\text { Autoclaving+ Lenzites elegans WDP2 } \\
\text { Culture }\end{array}$ & $68.5 \pm 0.09 * * * *$ & $20.7 \pm 0.39 * * * *$ \\
\hline$\overline{\text { ii }}$ & Autoclaving+ laccase enzyme & $65.0 \pm 0.16 * * * *$ & $20.8 \pm 0.40 * * * *$ \\
\hline III. & \multicolumn{3}{|l|}{ Chemical + biological treatments } \\
\hline$\overline{\mathbf{i}}$ & $\begin{array}{l}\mathrm{H}_{2} \mathrm{O}_{2}+\mathrm{NaOH}+\text { Lenzites elegans } \\
\text { WDP2 whole cell culture }\end{array}$ & 76.6 $\pm 1.00 * * * *$ & $\mathbf{1 4 . 5} \pm 0.06 * * * *$ \\
\hline ii & $\mathrm{H} 2 \mathrm{O} 2+\mathrm{NaOH}+$ laccase enzyme & $64.8 \pm 0.02 * * * *$ & $20.5 \pm 0.33 * * * *$ \\
\hline iii & $\begin{array}{l}\mathrm{NaOH}+\text { Lenzites elegans } \\
\text { whole cell culture }\end{array}$ & $70.2 \pm 0.30 * * * *$ & $20.1 \pm 0.71 * * * *$ \\
\hline iv & $\mathrm{NaOH}+$ laccase enzyme & $74.8 \pm 1.41 * * * *$ & $20.0 \pm 0.01 * * * *$ \\
\hline IV. & \multicolumn{3}{|c|}{ Physical + chemical + biological treatments } \\
\hline $\mathbf{i}$ & $\begin{array}{l}\mathrm{H} 2 \mathrm{O} 2+\mathrm{NaOH}+\text { Autocalving }+ \text { Lenzites } \\
\text { elegans } \mathrm{WDP} 2 \text { whole cell culture }\end{array}$ & $72.6 \pm 0.31 * * * *$ & $19.8 \pm 1.40 * * * *$ \\
\hline ii & $\begin{array}{l}\mathrm{H} 2 \mathrm{O} 2+\mathrm{NaOH}+\text { Autoclaving }+ \text { laccase } \\
\text { enzyme }\end{array}$ & $70.0 \pm 0.23 * * * *$ & $19.9 \pm 0.79 * * * *$ \\
\hline$\overline{\mathbf{V}}$. & Control (untreated) & $44.2 \pm 2.15$ & $28.9 \pm 2.26$ \\
\hline $\begin{array}{l}\mathrm{SEm} \pm \\
\mathrm{CD}(5 \%)\end{array}$ & & $\begin{array}{l}0.556 \\
1.65\end{array}$ & $\begin{array}{l}0.318 \\
0.945\end{array}$ \\
\hline
\end{tabular}

